\title{
Dosage de la testostérone plasmatique chez l'homme
}

\author{
H. LEJEUNE*, H. DECHAUD** \\ *Clinique Endocrinologique et **Laboratoire Central de Biochimie, Hôpital de l'Antiquaille, Lyon.
}

\section{RESUME}

Le principe des diverses méthodes de dosage de la testostérone et de ses formes circulantes est décrit : $1^{\circ}$ - dosage radioimmunologique de la testostérone totale avec un traceur tritié, après extraction des stéroïdes et chromatographie (méthode de référence), $2^{\circ}$ - méthodes de dosage directes dans le plasma, $3^{\circ}$ - dosage de la testostérone non liée à la SBP (fraction biodisponible pour les cellules cibles), utile dans les cas de modifications de la concentration plasmatique de SBP (hyperthyroïdie, andropause, insuffisance testiculaire exocrine sévère), $4^{\circ}$ dosage de la testostérone libre. Il existe des fluctuations épisodiques et un rythme nycthéméral de la testostéronémie, de larges variations inter-sujets et une diminution très progressive avec l'âge.

Mots clés : Testostérone, Sex steroid-binding protein, testostérone biodisponible, immunodosage, hypogonadisme, andropause.

\section{INTRODUCTION}

La testostérone est le principal androgène circulant chez l'homme, son dosage dans le plasma permet d'évaluer la fonction endocrine du testicule.

Pendant la vie intra-utérine, la testostérone sécrétée sous l'effet de l'hCG maternelle puis de la LH fotale permet la différencia- tion sexuelle masculine, la descente testiculaire et la croissance du pénis. Dans les 3 premiers mois de la vie, il existe une activation de l'axe gonadotrope avec sécrétion de testostérone. Les concentrations plasmatiques sont alors de l'ordre de la moitié de celles observées chez l'adulte. Pendant l'enfance, la testostérone est basse en raison de la mise au repos de l'axe gonadotrope. Lors de l'installation de la puberté, la testostérone augmente. Elle provoque alors la mise en place des caractères sexuels secondaires, participe à l'initiation de la spermatogénèse et permet l'apparition de la sexualité adulte. Avec l'avancée en âge, on constate une diminution statistique de la testostérone plasmatique avec des variations individuelles importantes.

La testostérone circule sous 3 formes :

- la testostérone liée à la protéine de liaison spécifique des stéroïdes sexuels, la Sex steroid-Binding Protein (SBP) encore appelée Sex Hormone-Binding Globulin (SHBG) ou Testosterone estradiol-Binding Globulin (TeBG),

- la testostérone liée à l'albumine,

- la testostérone libre.

La répartition de la testostérone entre ces 3 formes circulantes dépend d'une part des affinités de la testostérone pour la SBP et l'albumine et d'autre part des concentrations de SBP, d'albumine, et des autres stéroïdes ( $5 \alpha$-dihydrotestostérone, estradiol) capables de se lier à ces protéines de liai- 
son. La forte affinité de la testostérone pour la SBP fait que celle-ci a plutôt pour fonction de retenir la testostérone dans la circulation. A l'opposé, la faible affinité de la liaison de la testostérone à l'albumine fait que la testostérone liée à l'albumine peut facilement s'en libérer, la fraction libre de la testostérone diffusant dans les cellules cibles. Ainsi, des variations de la SBP peuvent modifier la quantité de testostérone circulante disponible pour les cellules cibles.

\section{METHODES DE DOSAGE DE LA TESTOSTERONE}

\section{Dosage de la testostérone totale}

C'est le plus souvent un immunodosage avec marqueur dans lequel il y a compétition entre la testostérone à doser (ou la testostérone étalon) et la testostérone marquée, vis à vis d'un nombre limité de sites anticorps anti-testostérone. A l'équilibre, les formes libre et liée à l'anticorps de la testostérone sont séparées. Le signal est ensuite mesuré (Figure 1).

a) Dosage radioimmunologique de la testostérone totale après extraction et chromatographie

Cette méthodologie, qui utilise la testostérone marquée au tritium, constitue, avec la spectrométrie de masse, une méthode de référence pour le dosage de cette hormone stéroïde.

En effet,

- L'extraction des stéroïdes du plasma par un solvant organique (éther diéthylique par exemple) permet d'éviter que l'interaction entre la testostérone et l'anticorps soit perturbée par les protéines du plasma et en particulier la SBP.

- La ${ }^{3} \mathrm{H}$-testostérone présentant une structure chimique identique à celle de la testostérone à doser est un traceur de choix : elle présente une immunoréactivité vis à vis de l'anticorps sensiblement identique à celle de la testostérone à doser ou de la testostérone étalon. Elle permet de procéder à des mesures du taux de récupération de la testostérone (les pertes possibles de testostérone lors de l'extraction et des étapes de chromatographie peuvent ainsi être estimées de manière précise sur chaque échantillon).

- La purification par chromatographie (chromatographie de partage, sur colonne de célite par exemple) permet de séparer la testostérone des autres stéroïdes susceptibles d'interférer au niveau du dosage radioimmunologique. En effet les structures chimiques des stéroïdes étant proches les unes des autres, la spécificité des anticorps anti-testostérone n'est pas absolue. Ces anticorps présentent en général certaines réactions croisées avec d'autres stéroïdes de structure proche de la testostérone.

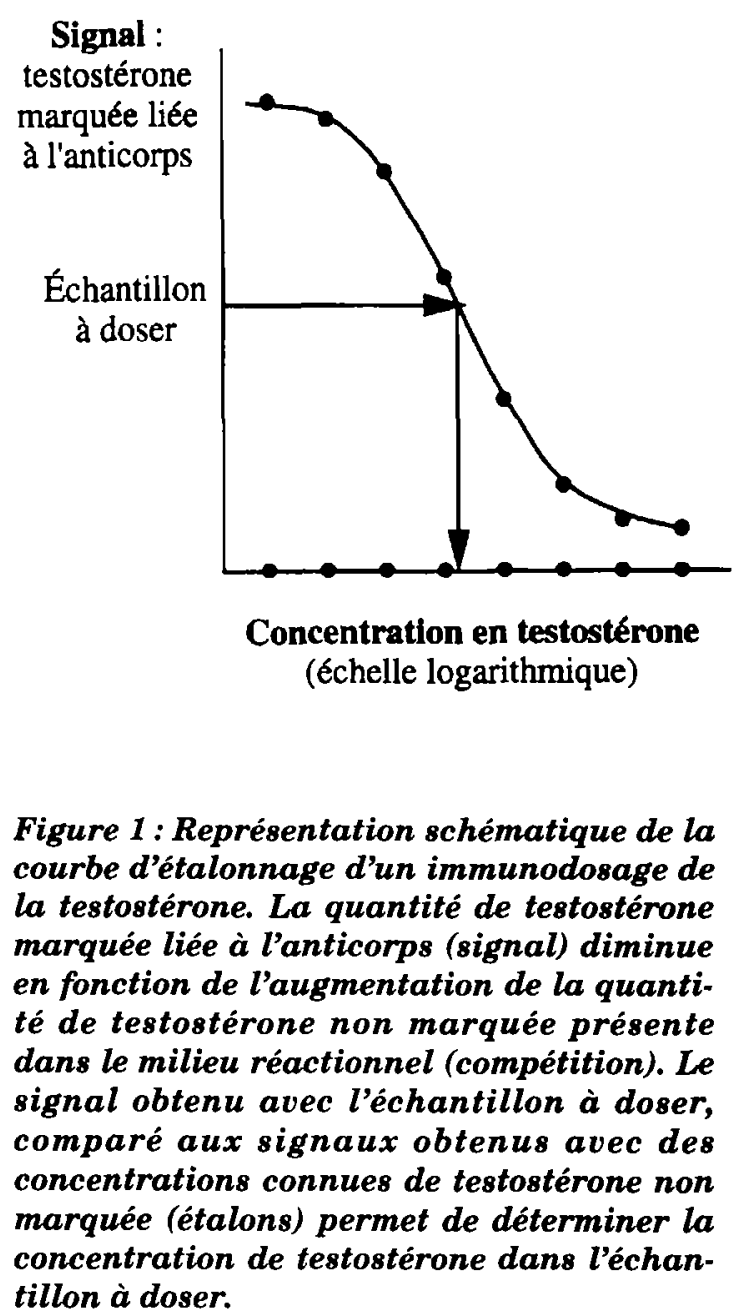


Les étapes d'extraction et de chromatographie permettent donc de supprimer en quasi-totalité les interférences spécifiques (réactions croisées) d'une part, les effets de matrice d'autre part (les molécules de testostérone à doser, comme les molécules de testostérone standard se trouvent alors environnées, lors du radioimmunodosage, par un milieu réactionnel identique, à savoir une solution tampon).

\section{b) Dosages de la testostérone par méthode directe}

Il existe des méthodes de dosage direct de la testostérone sur le plasma (ou le sérum). Ces méthodes, sans extraction, ni chromatographie, utilisent des anticorps fixés sur une phase solide et des marqueurs radioactifs (125I), luminescents (esters d'acridinium, luminol, $\mathrm{Eu}^{3+}$ ) ou enzymatiques (phosphatase alcaline, peroxydase).

Ces méthodes, précises et de pratique aisée, sont souvent automatisables. Cependant, soumises aux effets de matrice (SBP, acides gras, ...) et aux interférences spécifiques (5 $\alpha$-dihydrotestostérone, $\Delta 4$ Androsténedione, ...) malgré l'utilisation d'anticorps monoclonaux, elles ont une exactitude moins bonne que les méthodes avec extraction et chromatographie.

\section{Dosages des différentes fractions de la testostérone circulante}

La fraction de la testostérone circulante biodisponible pour les cellules cibles serait la fraction de la testostérone non liée à la SBP. Cette fraction comprend donc la testostérone libre ( 1 à $2 \%$ de la testostérone totale) capable de traverser les membranes des cellules cibles, et la testostérone liée à l'albumine, rapidement mobilisable à cause de la faible affinité de la liaison albuminetestostérone. Divers dosages ou index permettent d'apprécier ces différentes fractions de la testostérone circulante :

\section{a) Mesure du rapport testostérone tota- le / SBP}

La SBP a longtemps été dosée grâce à sa propriété de lier la testostérone ou la $5 \alpha$ - dihydrotestostérone tritiée. Elle peut maintenant être dosée par des méthodes immunologiques.

Le rapport testostérone totale / SBP permet de tenir compte de la concentration de la SBP dans l'interprétation de la concentration de testostérone, donc d'évaluer grossièrement la concentration de testostérone biodisponible. Il est à noter que si les laboratoires fournissent des normes pour les dosages de testostérone totale et de SBP, ils n'en fournissent en général pas pour le rapport testostérone totale / SBP.

\section{b) Testostérone non liée à la SBP}

Dans le plasma, il est possible de précipiter la SBP et la testostérone qui lui est liée par du sulfate d'ammonium à $50 \%$ de saturation. L'albumine n'est pas précipitée à cette concentration de sulfate d'ammonium (Figure 2). Le dosage de la testostérone restant dans le surnageant permet une mesure de la testostérone non liée à la SBP, c'est à dire la somme testostérone liée à l'albumine + testostérone libre, ce qui représente finalement la fraction biodisponible pour les cellules cibles [2].

L'exemple le plus frappant de modification des fractions circulantes de la testostérone est certainement l'hyperthyroïdie chez l'homme. Il est fréquent que les patients présentant une maladie de Basedow se plaignent d'une impuissance sexuelle et développent une gynécomastie, le tout évoquant un hypogonadisme. Chez ces patients, la concentration de testostérone totale est supérieure aux normes. Ce paradoxe s'explique par l'effet stimulant direct des hormones thyroidiennes sur la sécrétion de SBP par le foie. Il en résulte une augmentation de la concentration de SBP dans le plasma, ce qui est responsable d'une augmentation de la concentration de testostérone liée à la SBP dans le plasma. En conséquence, les valeurs de la testostérone non liée à la SBP sont basses, proches de celles observées dans les hypogonadismes, donc en bonne concordance avec la clinique (Figure 3). 


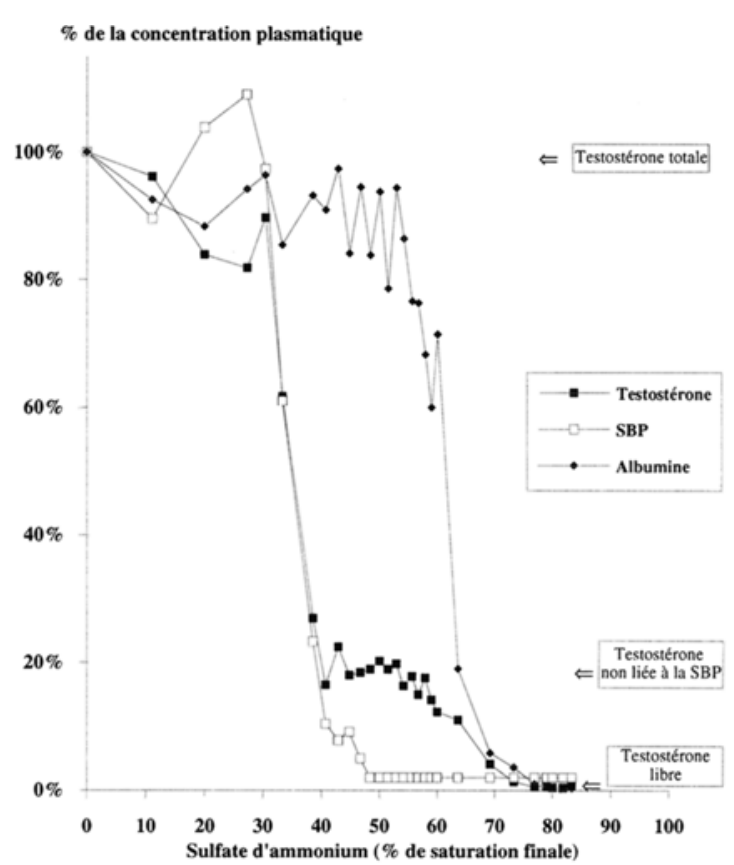

Figure 2 : Concentrations de SBP, d'albumine et de testostérone dans le surnageant d'un plasma après précipitation par des concentrations croissantes de sulfate d'ammonium.

\section{c) Testostérone libre}

Il est possible de mesurer le pourcentage de testostérone libre (\%Tlibre) dans le plasma par dialyse à l'équilibre à l'aide de testostérone marquée au tritium. Connaissant la concentration de testostérone totale $(\mathrm{T})$, le produit T x \% Tlibre permet de calculer la concentration en testostérone libre. Cette méthode de référence est trop lourde à mettre en œuvre pour être utilisée en routine.

Depuis quelques années des immunodosages de la testostérone libre utilisant des "traceurs analogues" ont été développés, non sans difficultés. Celles-ci sont dues :

- à la faible quantité de testostérone libre à doser,

- à la grande quantité d'albumine, protéine de liaison qui présente une faible affinité pour la testostérone,

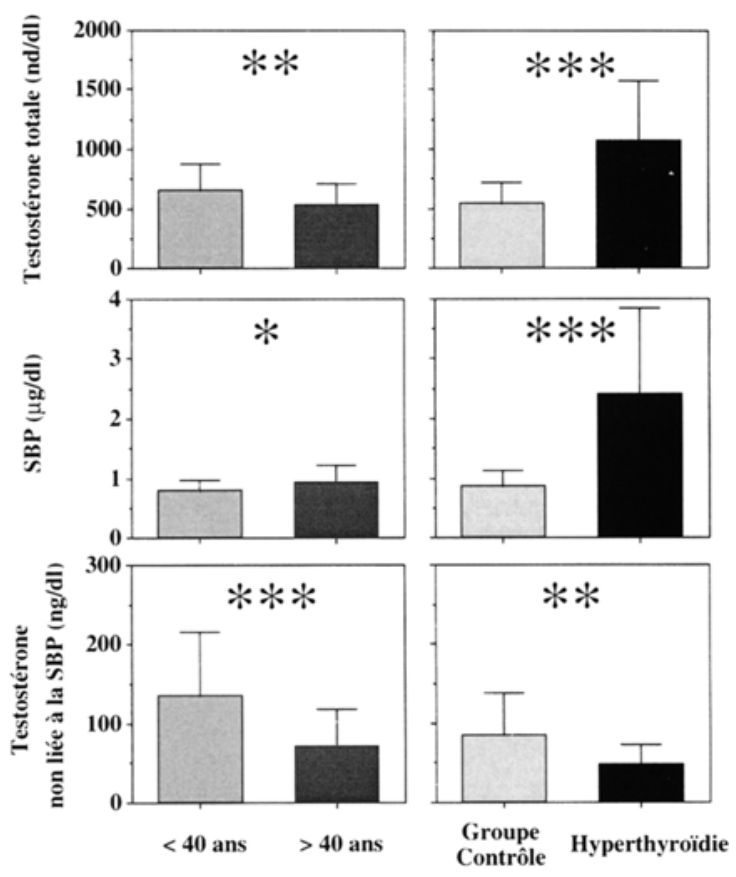

Figure 3 : Valeurs $(m \pm 1 D S)$ de la testostérone totale, de la SBP et de la testostérone non liée à la SBP chez 30 sujets normaux âgés de 18 à 40 ans (< 40 ans), 35 sujets normaux âgés de 40 à 83 ans (> 40 ans), 18 patients ágés de 29 à 79 ans présentant une hyperthyroïdie et 18 sujets normaux appariés pour l'âge aux sujets présentant une hyperthyroüdie (Groupe Contrôle). ${ }^{*} p<0,05$; * $p<0,01$; ** $p<0,001$ pour le test $t$ de Student. (ref. Déchaud et al., 1989)

- au fait que l'on utilise une méthode directe de dosage avec ses inconvénients classiques, interférences spécifiques et effets de matrice.

\section{d) Coût des dosages :}

Dosage de testostérone totale dans le plasma : $\quad$ B $80=140,80 \mathrm{~F}^{*}$

Dosage de SBP dans le plasma :

$$
\text { B } 80=140,80 \mathrm{~F}^{*}
$$

Dosage de testostérone biodisponible dans le plasma : $\quad \mathrm{B} 140=246,40 \mathrm{~F}^{*}$

Dosage de testostérone libre dans le plasma : $\quad$ B $140=246,40 \mathrm{~F}^{*}$ * : pour une valeur actuelle du B de 1,76 F. 
Ces dosages sont remboursés par la Sécurité Sociale.

\section{VARIATIONS DE LA TESTOSTERONE SERIQUE}

Chez l'homme, l'indication du dosage de testostérone correspond à la recherche d'une altération de la fonction endocrine du testicule, primitivement testiculaire ou secondaire à une altération centrale (hypothalamo-hypophysaire). L'interprétation de la testostéronémie doit tenir compte de certains facteurs de variabilité :

\section{Cycle nycthéméral et pulsatilité}

La sécrétion de testostérone par la cellule de Leydig est directement sous l'influence de la LH. La sécrétion pulsatile de GnRH par l'hypothalamus induit une sécrétion pulsatile de LH qui est elle même responsable de variations épisodiques de la testostérone sérique (Figure 4). Il existe en outre une variation nycthémérale de la testostérone avec un maximum le matin, une diminution au cours de la journée (Figure 4) et une remontée en fin de nuit. Le mécanisme de cette variation nycthémérale tient dans une variation de la sensibilité de la cellule de Leydig à la $\mathrm{LH}$ (il n'existe pas de variation nycthémérale de la LH en dehors de la période d'installation de la puberté). La conséquence pratique découlant de la variation nycthémérale est la nécessité de faire pratiquer le dosage de testostérone le matin, les valeurs de l'après-midi étant régulièrement plus basses de l'ordre de $50 \%$.

\section{Variations inter-sujets de la concen- tration de la testostérone plasmatique}

La valeur de la testostérone varie largement selon les individus. Les valeurs normales s'étalent entre 300 et $1000 \mathrm{ng} / \mathrm{dl}$. Le niveau auquel est maintenue la concentration de testostérone semble pour une part sous contrôle génétique. Les variations entre sujets d'une même fratrie apparaissent inférieures à la variabilité dans la population générale.

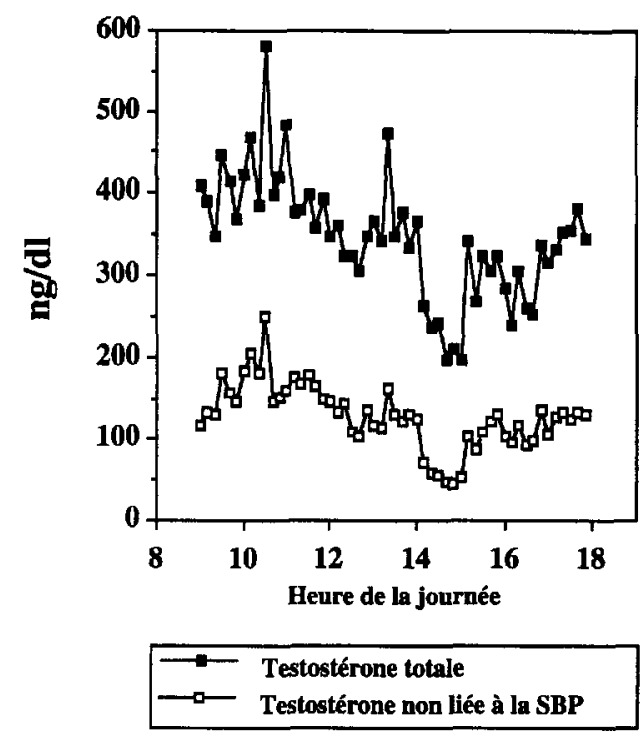

Figure 4 : Variations de la testostérone totale et de la testostérone non liée à la SBP mesurée toutes les 10 minutes au cours de la journée chez un homme normal.

\section{Modifications avec l'âge}

En moyenne, la concentration plasmatique de testostérone diminue de manière progressive avec l'âge. Il existe toutefois de grandes variations de la testostéronémie entre les sujets dans chaque tranche d'âge. Ainsi, certains sujets de plus de 70 ans ont une concentration de testostérone supérieure à celles d'hommes jeunes. Il apparaît que la diminution de la testostérone est liée au vieillissement lui-même et pas seulement aux états pathologiques plus fréquents chez les sujets âgés. Avec l'âge, le nombre de cellules de Leydig diminue, la réponse à l'hCG diminue, la LH augmente mais perd de sa bioactivité [5].

\section{Modifications de la SBP}

L'intervention de la SBP dans la biodisponibilité de la testostérone pour les cellules cibles oblige à tenir compte des variations concomitantes des concentrations de testostérone et de SBP, en particulier dans les situations suivantes : 
a) Hyperthyrö̈die : nous avons vu les conséquences de l'augmentation de la SBP due à l'excès d'hormone thyroïdienne. La testostérone totale est augmentée mais retenue dans la circulation. La testostérone non liée à la SBP est abaissée en accord avec la symptomatologie comportant des signes d'hypogonadisme.

b) Puberté : Au cours de la puberté, la production de testostérone augmente du fait de l'activation de l'axe gonadotrope. De manière concomitante, la SBP diminue [3].

c) Variation de poids : la concentration plasmatique de SBP est contrôlée par des facteurs métaboliques : elle est diminuée dans les cas d'obésité, augmentée chez le sujet dénutri.

d) Vieillissement : Au cours du vieillissement la SBP augmente progressivement. La testostérone non liée à la SBP diminue de manière souvent plus importante que ne le laisserait prévoir la mesure de la testostérone totale (Figure 3).

\section{e) Insuffisances testiculaires exocrines} sévères : Dans les insuffisances testiculaires exocrines sévères avec atrophie testiculaire et forte élévation de la FSH (au maximum dans le syndrome de Klinefelter), la testostérone totale est dans les limites inférieures de la normale. En revanche, la testostérone non liée à la SBP est souvent nettement inférieure à la normale en raison d'une augmentation de la SBP.

\section{LES HYPOGONADISMES}

Des concentrations de testostérone inférieures à $250 \mathrm{ng} / \mathrm{dl}$ chez l'adulte jeune sont évocatrices d'une altération de la fonction endocrine du testicule. Le dosage des gonadotrophines permet de rapporter l'hypogonadisme à une atteinte périphérique testiculaire en cas d'élévation de la LH. Les atteintes testiculaires périphériques portant de manière prédominante sur la fonction exocrine, la FSH sera le plus souvent élevée. L'association d'un abaissement de la testostérone et de taux bas de LH (et de FSH) signe une atteinte centrale, avec une insuffisance leydigienne en général plus marquée que dans les atteintes testiculaires périphériques [6]. Certaines circonstances sont responsables d'un hypogonadisme fonctionnel [1], c'est le cas du stress. Par exemple, une intervention chirurgicale provoque une diminution de la testostéronémie qui peut mettre plusieurs semaines pour se normaliser.

\section{TESTOSTERONE ET SEXUALITE}

S’il est incontestable que la testostérone intervient dans la sexualité masculine, la relation entre "performances" sexuelles et testostéronémie n'apparaît toutefois pas linéaire. Diverses études ont recherché le mode de relation entre testostérone et sexualité [4]. Il semble exister une valeur seuil au-dessous de laquelle apparaissent des troubles sexuels. Au-dessus de cette valeur seuil, l'imprégnation hormonale parait suffisante pour permettre une sexualité normale quelle que soit la valeur de la testostéronémie. Ce seuil apparaît cependant variable d'un sujet à l'autre, en particulier en fonction de l'expérience sexuelle et de l'environnement affectif du sujet. Une des questions qui se pose fréquemment est de savoir à partir de quelle valeur de testostéronémie on peut considérer que les troubles sexuels d'un sujet sont en rapport avec le déficit androgénique lié à l'âge. Les multiples facteurs intervenant de manière positive ou négative sur la sexualité masculine font que la détermination de la valeur seuil d'apparition des troubles sexuels est très difficile à préciser et qu'il est parfois nécessaire de réaliser un test thérapeutique, à condition que l'utilisation d'androgène ne soit pas contre-indiquée, en particulier par une pathologie prostatique.

\section{REFERENCES}

1. DE LIGNIERE B., VINCENS M. : Variations fonctionnelles de l'activité testiculaire. In : Mauvais Jarvis P., Schaison G., Bouchard P., Mahoudeau J., Labrie F. eds. Médecine de la reproduction masculine. Paris, Flammarion, Médecine Sciences, 1984 : 441-447. 
2. DECHAUD H., LEJEUNE H., CHOLLET M., MALLEIN R., PUGEAT M. : Radioimmunoassay of testosterone not bound to sex steroid-binding protein in plasma. Clin. Chem. 1989, $35: 1609-1614$.

3. FOREST M.G. : Modifications hormonales et mécanismes neuroendocriniens de la puberté. In : La puberté masculine et ses pathologies. Progrès en Andrologie. Paris, Doin eds, 1993 ; 4 : 7-23.

4. HUBERT W. : Psychotropic effects of testosterone. In : Nieschlag E., Behrer H.M. eds. Testosterone : action, deficiency, substitution. Berlin, Heidelberg, New York, Springer-Verlag, $1990: 51-71$.

5. LEJEUNE H., DÉCHAUD H., PUGEAT M. : Évolution de l'axe hypothalamo-hypophyso-testiculaire au cours du vieillissement. Contracept. Fertil. Sex., $1991 ; 19$ : 951-957.

6. SCHAISON G., VALCKE J.C. HYPOGONADISMES. IN : MAUVAIS JARVIS P., SCHAISON G., BOUCHARD P., MAHOUDEAU J., LABRIE F. EDS. : Médecine de la reproduction masculine. Paris, Flammarion, Médecine Sciences, 1984 : 251 290.

\section{ABSTRACT \\ Plasma testosterone assay in men.}

Hervé LEJEUNE, Henti DECHAUD.

The measurement of testosterone in plasma is the main tool to investigate the endocrine function of the testis. Radioimmunoassay of total testosterone using ${ }^{3} H$-testosterone as tracer, after steroid extraction and chromatography avoids the interactions of steroids and plasma proteins in the assay. It can be considered as a method of reference. Direct methods, without extraction and chromatography, and using non-radioactive tracers have been developped. They are easier and faster to perform but less accurate because of the aforementioned interactions. In the plasma, testosterone is mainly bound with a high affinity to SBP and with a low affinity to albumin. Non-SBP-bound testosterone is considered to represent the fraction of the testosterone available for target cells. Non-SBP-bound testosterone can be measured after precipitation of SBP by ammonium sulfate. This procedure is usefull to investigate androgenicity when plasma SBP concentrations are altered such as in hyperthyroidism, aging and severe exocrine testicular failure. Plasma free testosterone can be mesured by equilibrium dialysis, a procedure not suitable for routine assay or more easily but less accuratly by direct measurement in the plasma with methods using tracer analogs. The interpretation of testosterone measurement must take into account moment-to-moment and nycthemeral variations. The inter-subject variations of plasma testosterone concentrations are large, the decrease with aging is very progressive. Testosterone has a permisive effect on male sexual function with a threshold level above which no relationship between plasma testosterone concentration and sexual "performances" could be demonstrated. Because of the multifactorial control of human sexual function, the threshold value is difficult to determine for a given patient.

Key words : Testosterone, sex steroid-binding protein, bioavailable testosterone, immunoassay, hypogonadism, aging. 